\title{
Extensor indicis proprius tendon transfer for extensor pollicis longus rupture
}

\author{
Achilleas Thoma MD FRCSC FACS, Adel Quttainah MD \\ Department of Surgery, Division of Plastic and Reconstructive Surgery, St Joseph's Hospital and \\ McMaster University, Hamilton, Ontario
}

\section{A Thoma, A Quttainah. Extensor indicis proprius tendon transfer for extensor pollicis longus rupture. Can J Plast Surg 2001;9(4):139-142.}

Six of 13 patients who underwent extensor indicis proprius (EIP) tendon transfer for extensor pollicis longus (EPL) rupture between 1985 and 1998 were available for long term assessment of the function of the thumb. The presenting problem was the inability to extend the thumb at the interphalangeal (IP) joint. Postoperatively, there was no extension lag at the IP joint of the thumb. Three patients had slightly reduced flexion at the IP joint compared with the unaffected thumb. Five patients showed no extension lag at the metacarpophalangeal (MCP) joint, whereas one patient had an extension lag of $28^{\circ}$. The mean active flexion at the IP joint of the thumb was $64.5^{\circ}\left(\mathrm{range} 50^{\circ}\right.$ to $77.5^{\circ}$ ). The mean extension deficit of the index finger at the MCP joint was $7^{\circ}$ (range $0^{\circ}$ to $20^{\circ}$ ) compared with the unaffected side that was $5^{\circ}$ (range $0^{\circ}$ to $12^{\circ}$ ). Measurements of key pinch and pinch grip were $94 \%$ and $82 \%$ in the unaffected hand, respectively. Subjective assessment by the patients was rated as excellent by four patients and good by two patients. This particular tendon transfer is recommended for the treatment of EPL rupture.

Key Words: Extensor indicis proprius; Extensor pollicis longus rupture; Tendon transfer

\section{Transposition tendineuse de l'extenseur propre de l'index pour rupture du muscle long extenseur du pouce}

RÉSUMÉ : Six patients sur treize ayant subi une transposition tendineuse de l'extenseur propre de l'index (EPI) pour rupture du muscle long extenseur du pouce (LEP) entre 1985 et 1998 ont participé à une évaluation à long terme du fonctionnement du pouce. Le problème consistait en l'incapacité d'étendre le pouce à l'articulation interphalangienne (IP). Après l'opération, il n'y avait pas d'incapacité d'extension totale (IET) à l'articulation IP du pouce. Trois patients présentaient une légère réduction de la flexion à l'articulation IP par rapport au pouce normal. Aucune IET à l'articulation métacarpo-phalangienne (MP) n'a été observée chez cinq patients, tandis qu'une IET de 28 a été notée chez un patient. La flexion active moyenne à l'articulation IP était de 64,5 (50 - 77,5 ). Le déficit moyen d'extension de l'index à l'articulation MP était de 7 ( 0 - $)$ comparativement au doigt de la main opposée, qui était de 5 (0 - 12 ). Les mesures de pincement latéral («key pinch ») et de pincement pollicidigital du côté normal étaient de $94 \%$ et de $82 \%$ respectivement. Quatre patients ont accordé la cote « Excellente » et deux autres, la cote « Très bonne » dans leur évaluation subjective. Il est donc recommandé de procéder à une transposition tendineuse de l'EPI pour traiter les ruptures du LEP.

$\mathrm{T}$ he extensor pollicis longus (EPL) tendon is one of the most frequently ruptured tendons. The EPL is the primary extensor of the interphalangeal (IP) joint of the thumb and is also important in metacarpophalangeal (MCP) joint extension. The loss of this tendon leads to an inability to extend the thumb and raise it to the level of the palm, leaving the patient with a useless thumb (1). Clinically, the examiner can no longer palpate or see the upper boundary of the anatomical snuffbox.
EPL tendon rupture was first mentioned by Duplay (2) in 1876. The etiology of EPL rupture is varied. Open injuries and lacerations to the tendon are a frequent cause of rupture. Distal radial fractures (displaced and nondisplaced) and rheumatoid arthritis are other frequent causes. Methods of reconstructing the tendon include direct repair, which is only possible if the laceration is recent, before myostatic contracture takes place, imposing a gap between disrupted tendon ends (3).

\footnotetext{
This paper was presented at the 54th Annual Meeting of the Canadian Society of Plastic Surgeons, Winnipeg, Manitoba, June 7 to 10, 2000 Correspondence and reprints: Dr Achilleas Thoma, 200 James Street South, Suite 208, Hamilton, Ontario L8P 3A9. Telephone 905-523-0019, fax905-523-0229, e-mail athoma@fhs.mcmaster.ca
} 


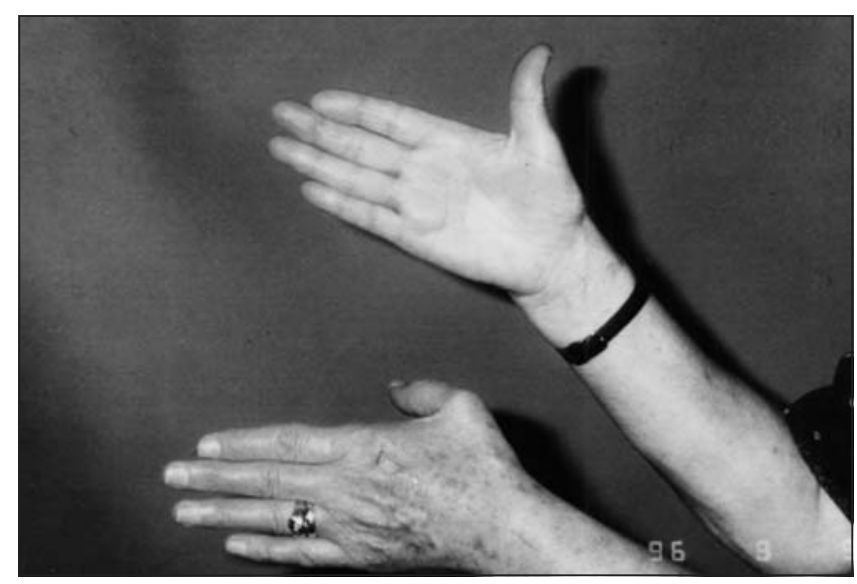

Figure 1) Typical thumb posture after spontaneous rupture of the extensor pollicis longus compared with a normal thumb

There are two general theories regarding delayed rupture of the EPL. In the vascular theory, a pressure build-up in the intact tendon sheath due to synovitis or a hematoma causes ischemia and the eventual rupture of the tendon (4). This would explain delayed EPL rupture in cases of nondisplaced distal radial fractures as opposed to displaced fractures where the tendon sheath is more likely to have been torn, thus, preventing an increase in pressure within the tendon sheath. A microangiographic study performed on cadavers by Hirasawa et al (5) revealed a poorly vascularized segment approximately $5 \mathrm{~mm}$ in length that may contribute to the rupture of the tendon around Lister's tubercle. This tendon devascularization most likely occurs in nondisplaced radial fractures in which the extensor retinaculum remains intact (6). The periosteal hypertrophy and callus formation lead to the narrowing of the third extensor compartment and compression of the EPL. This compression leads to further tendon vascular compromise and disruption of synovial fluid from the synovial sheath where the tendon receives most of its nourishment. This compromise eventually leads to degenerative necrosis of the tendon.

The mechanical theory states that the EPL tendon is severed by the ends of broken bone or because of attrition of the tendon around Lister's tubercle. In 1923, Ashurst (7) also reported that the tendon becomes adherent to the callus and then yields as a result of straining.

McMaster (8) performed end-to-end repair with subcutaneous rerouting to regain the relative length of the tendon. Interpositional tendon grafts are another modality of treatment. Platt (9) used a toe extensor tendon as a graft. Hamlin and Littler (3), and Magnell et al (10) recommended the use of the palmaris longus tendon. Problems with tendon grafts include avascular necrosis of the graft and the possibility of failure at the proximal or distal suture junctions. Palmaris longus is the most commonly used tendon graft. Other tendon grafts that are used include the extensor hallucis longus, plantaris and flexor digitorum superficialis of the little finger.

Various tendon transfers have also been used as a solution to EPL rupture. These include extensor indicis proprius (EIP), extensor carpi radialis longus, extensor pollicis brevis and palmaris longus. The EIP tendon transfer seems to be the preferred option by some authors (11-14); however, it is not uniformly accepted as the best procedure. This may be due to the fear of disabling the adjacent index finger through an unwanted extensor lag of the MCP joint.

This small retrospective series, in addition to providing evidence of the salutory effect of this tendon transfer, also adds information on the extension lag of the donor index finger.

\section{PATIENTS AND METHODS}

Thirteen patients with the diagnosis of EPL rupture underwent surgery for an EIP tendon transfer between 1985 and 1998. Follow-up ranged from three months to 14 years (mean 3.1 years) after surgery. There were seven men and six women. Their ages ranged from 23 to 67 years (mean 51.9 years). The dominant hand was involved in six patients. The cause of EPL rupture was distal radial fracture in seven patients, five of these fractures were Colles' fractures. The remainder of causes were gouty arthritis, rheumatoid arthritis, reconstruction after resection of a malignant fibrous histiocytoma of the thumb and blunt trauma. In one patient, the cause of EPL rupture was unknown.

The time between injury and the diagnosis of EPL rupture was brief in four patients. It ranged between three weeks and three months (mean 7.6 weeks) in five patients, and was uncertain in three patients. The predominant complaints by the afflicted patients were the inability to extend the thumb and difficulty in elevating the thumb to the palm level (Figure 1). Some patients also complained of local discomfort, pain and swelling at the dorsum of the wrist. An attempt was made to recontact all 13 patients for functional evaluation. Patient contact was attempted by telephone and mailing address (obtained from hospital or office medical records), and by enquiring with the patients' last known family physician. Six patients were contacted. The remaining seven patients could not be contacted because they had left the Hamilton area.

\section{Surgical technique}

All surgeries were performed under general anesthesia, with tourniquet control. A transverse incision was made over the dorsum of the second MCP joint, and the EIP tendon was isolated on the ulnar side from the extensor indicis communis and was transected. The stump of the distal end of the EIP was then sutured to the remaining communis tendon to the index finger in a side to side manner to maintain the centralization of the extensor digitorum communis. Sometimes a second transverse incision was made over the base of the second metacarpal bone, through which the tendon was withdrawn. The extensor retinaculum over the fourth compartment was released to allow a direct line of pull. Another incision was made longitudinally over the anatomical snuffbox and the base of the thumb metacarpal to identify the distal end of the ruptured EPL. A tunnel was then created in the subcutaneous tissue, deep to the branches of the radial nerve and the cephalic vein. The EIP tendon was then retrieved through this exposure. A Pulvertaft repair was performed using 4-0 nylon sutures (Figure 2). After the 


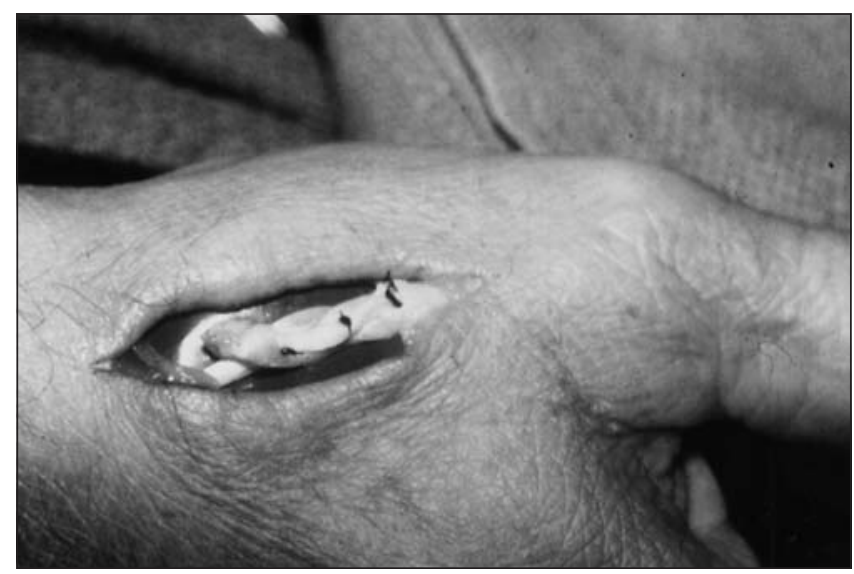

Figure 2) Pulvertaft tendon weave technique providing strong tendon repair

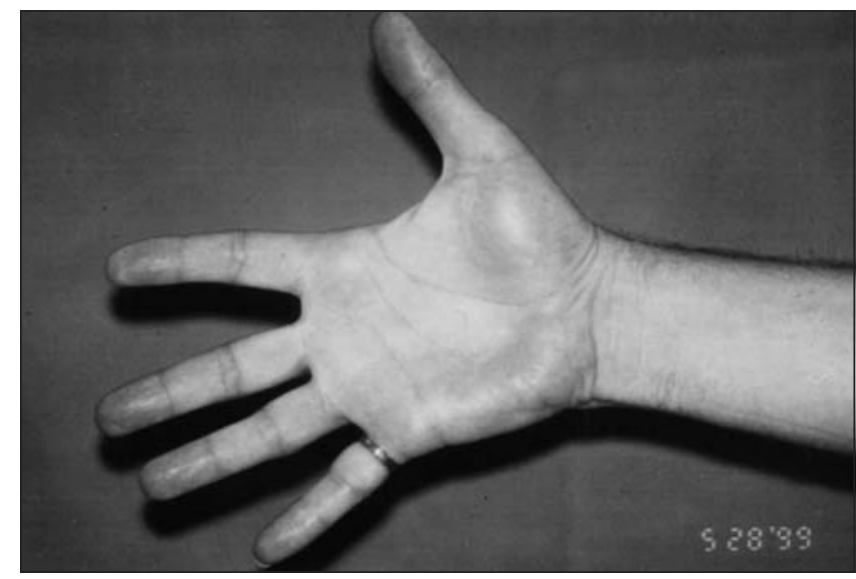

Figure 3) Long term extensor indicis proprius to extensor pollicis longus tendon transfer showing excellent results

TABLE 1

Follow-up range of motion assessment (expressed as affected hand [A] to normal hand [N]) for six of 13 patients who underwent extensor indicis proprius tendon transfer

\begin{tabular}{|c|c|c|c|c|c|c|c|c|c|c|c|c|c|c|}
\hline Patient & Sex & $\begin{array}{c}\text { Age } \\
\text { (years) }\end{array}$ & $\begin{array}{c}\text { Dominant } \\
\text { hand }\end{array}$ & $\begin{array}{c}\text { Affected } \\
\text { hand }\end{array}$ & $\begin{array}{c}\text { Flexion } \\
\text { at thumb } \\
\text { MCP } \\
(\mathrm{A}[\mathrm{N}])\end{array}$ & $\begin{array}{c}\text { Extension } \\
\text { lag at } \\
\text { thumb } \\
\text { MCP } \\
\text { (A[N]) }\end{array}$ & $\begin{array}{c}\text { Flexion at } \\
\text { thumb IP } \\
(\mathrm{A}[\mathrm{N}])\end{array}$ & $\begin{array}{c}\text { Extension } \\
\text { lag at } \\
\text { thumb IP } \\
(\mathrm{A}[\mathrm{N}])\end{array}$ & $\begin{array}{c}\text { Radial } \\
\text { abduction } \\
(\mathrm{A}[\mathrm{N}])\end{array}$ & $\begin{array}{c}\text { Opposition } \\
\text { distance } \\
(\mathrm{cm}) \\
(\mathrm{A}[\mathrm{N}])\end{array}$ & $\begin{array}{c}\text { Pinch grip } \\
\text { (kg) } \\
(\mathrm{A}[\mathrm{N}])\end{array}$ & $\begin{array}{c}\text { Key pinch } \\
(\mathbf{k g}) \\
(\mathrm{A}[\mathrm{N}])\end{array}$ & $\begin{array}{l}\text { Extension } \\
\text { lag at } \\
\text { index } \\
\mathrm{MCP} \\
\mathrm{A}(\mathrm{N})\end{array}$ & $\begin{array}{c}\text { Patient } \\
\text { outcome }\end{array}$ \\
\hline 1 & M & 74 & $\mathrm{R}$ & $\mathrm{R}$ & $22.5(50)$ & $28(28)$ & $55(77.5)$ & $0(32)$ & $65(66)$ & $7(0)$ & $7.26(7.72)$ & $6.81(8.63)$ & $0(12)$ & Good \\
\hline 2 & $\mathrm{~F}$ & 69 & $\mathrm{R}$ & $\mathrm{L}$ & $40(62.5)$ & $0(0)$ & $52(65)$ & $0(0)$ & $62.5(65)$ & $1.5(0)$ & $3.63(6.81)$ & $6.36(6.36)$ & $0(0)$ & Excellent \\
\hline 3 & $\mathrm{~F}$ & 70 & $\mathrm{R}$ & $\mathrm{L}$ & $55(60)$ & $0(0)$ & $50(50)$ & $0(0)$ & $70(70)$ & $0(0)$ & $4.54(4.99)$ & 4.99 (4.99) & $20(0)$ & Good \\
\hline 4 & M & 43 & $\mathrm{R}$ & $\mathrm{R}$ & $30(50)$ & $0(0)$ & $87.5(70)$ & $0(0)$ & $90(92.5)$ & $0(0)$ & $4.54(6.36)$ & $7.72(7.72)$ & $10(0)$ & Excellent \\
\hline 5 & $M$ & 66 & $\mathrm{R}$ & $\mathrm{R}$ & $50(70)$ & $0(0)$ & $48(50)$ & $0(0)$ & $72(74)$ & $0(0)$ & $9.08(10.90)$ & $10.44(11.35)$ & $4(3)$ & Excellent \\
\hline 6 & $\mathrm{~F}$ & 37 & $\mathrm{R}$ & $\mathrm{L}$ & $56(57.5)$ & $0(0)$ & $40(75)$ & $0(0)$ & $72(70)$ & $0(0)$ & $6.81(6.81)$ & $6.36(6.81)$ & $8(8)$ & Excellent \\
\hline
\end{tabular}

F Female; IP Interphalangeal opposition distance; L Left; M Male; MCP Metacarpophalangeal; R Right

procedure, the thumb was placed in a plaster splint extending to the tip of the thumb for four weeks that allowed free motion of the index finger. In patients with rheumatoid arthritis, an extensor tenosynovecomy was also performed.

\section{Assessment}

Active flexion and extension at both the MCP and IP joints of the thumb were measured using a goniometer. Extension lag at the index finger and radial abduction of the thumb were also measured. Pinch grip and key pinch were measured using a pinch dynamometer. Opposition distance, which is the distance between the distal end of the thumb and the fifth MCP joint, was also measured. All assessments were performed by an independent assessor.

\section{RESULTS}

The range of motion, and grip and pinch strength measurements are shown in Table 1. There was no extension lag of the IP joint of the thumb. Three patients had slightly reduced flexion at the IP joint of the thumb compared with the unaffected hand, with a mean of $55.4^{\circ}$ (range $40^{\circ}$ to $87.5^{\circ}$ for all six patients) compared with the unaffected side, which had a mean of $64.5^{\circ}$ (range $50^{\circ}$ to $77.5^{\circ}$ ). Five patients did not have any extension lag at the MCP joint of the thumb (Figure 3). Patient 1 had an extension lag of $28^{\circ}$. All patients had radial abduction that was comparable with the normal side. Four patients had an opposition distance of $0 \mathrm{~cm}$ (ie, normal). Patients 1 and 2 had oppositon distances of $7 \mathrm{~cm}$ and $1.5 \mathrm{~cm}$, respectively. Patient 1 had a crush injury to his right hand with extensive soft tissue involvement. He also developed reflex sympathetic dystrophy, thus, explaining his extension lag of $28^{\circ}$ at the MCP joint of the thumb and his opposition distance of $7 \mathrm{~cm}$.

The mean extension deficit at the MCP joint of the index finger on the affected side was $7^{\circ}$ (range $0^{\circ}$ to $20^{\circ}$ ) and that of the normal side was $5.5^{\circ}$ (range $0^{\circ}$ to $12^{\circ}$ ). Pinch grip and key pinch as a function of thumb strength of the affected hand were $82 \%$ (range $53.3 \%$ to $100 \%$ ) and $94 \%$ (range $79 \%$ to $100 \%$ ) of the unaffected hand, respectively. Four patients reported an excellent outcome. Patient 1 had difficulty with grasping scissors and patient 3 reported some difficulty with picking up objects; however, both patients graded their outcome as good. 


\section{DISCUSSION}

Key pinch and pinch grip as a measure of thumb strength and function showed comparable results with those of the unaffected side.

The only reported problem with the use of EIP was weakness and extensor lag of the index finger (15). This was disputed, however, in a larger study of 27 EIP transfers with no evidence of extension lag (16). A minor extension lag of $10^{\circ}$ and $20^{\circ}$ occurred in patients 3 and 4 , respectively. Neither patient complained of any functional disability, however. For all purposes, this extension lag was inconsequential. Repair of the extensor hood by side-to-side suture of the distal remaining stump of the EIP to the extensor digitum communis is recommended. This procedure maintains centralization of the EDC over the MCP joint and prevents its gradual migration with a consequent extension lag.

The length of the EIP permits one to perform at least three weaves with the stump of the EPL tendon by using the Pulvertaft technique, thus, diminishing the chance of a spontaneous dehiscence at the tendon juncture. This cannot be said of

\section{REFERENCES}

1. Schneider LH, Rosenstein RG. Restoration of extensor pollicis longus function by tendon transfer. Plast Reconstr Surg 1983;71:533-7.

2. Dupley S. Rupture sous-cutance du tendon du long extenseur du ponce de la main droite au niveau de la tabatiere anatomique. Bull Mem Soc Chir 1876;2:788.

3. Hamlin C, Littler JW. Restoration of the extensor pollicis longus tendon by an intercalated tendon graft. J Bone Joint Surg [Am] 1977;59:412-4.

4. Noordanus RP, Pot JH, Jacobs PBD, Stevens K. Delayed rupture of extensor pollicis longus tendon: a retrospective study. Arch Orthop Trauma Surg 1994:113:164-6.

5. Hirasawa Y, Katsumi Y, Akiyoshi T, Tamai K, Tokioka T. Clinical and microangiographic studies on rupture of the EPL tendon after distal radial fractures. J Hand Surg [Br] 1990;15:51-7.

6. Helal B, Chen SC, Iwefbu G. Rupture of extensor pollicis longus tendon in undisplaced Colles' type of fracture. Hand 1982;14:41-7.

7. Ashhurst APC. Rupture of tendon extensor longus pollicis following a Colles' fracture. Ann Surg 1923;78:398-400.

8. McMaster PE. Late rupture of extensor and flexor pollicis longus tendons following Colles' fracture. J Bone Joint Surg [Am] 1932;14:93-101. the extensor carpi radialis longus, another possible transfer due to its shorter reach. The ease of harvest and transfer of the synergistic EIP to EPL tendon makes this transfer the preferred method at the authors' institution.

\section{CONCLUSIONS}

A long term assessment of the EIP tendon transfer showed a very good outcome. Index finger extension lag has not been an issue with the authors' patients compared with those in other studies. Releasing the extensor retinaculum of the fourth extensor compartment and subcutaneous rerouting of the EIP allow a direct line of pull in a direction similar to that of the EPL tendon. The authors recommend EIP tendon transfer for EPL rupture; it is a simple procedure that yields an excellent functional outcome with minimal complications.

ACKNOWLEDGEMENTS: The authors thank Karen Veltri MSc for her technical assistance in preparing this manuscript.

9. Platt H. Observations of some tendon ruptures. Br Med J 1931;1:611-5.

10. Magnell TD, Pochron MD, Condit DP. The intercalated tendon graft for treatment of extensor pollicis longus tendon rupture. J Hand Surg 1988;13:105-9.

11. Albers U, Bultman U, Buck-Gramcko D. Ersatz der langen Daumenstreckschne durch Umalgerung des seigefinger streckers. Handchir Mikrochir Plast Chir 1992;24:124-30.

12. Hoch J, Loseh GM, Schrader M. Langzeitresultate nach rekonstruktion der sehne des $\mathrm{M}$ extensor pollicis longus durch transposition der sehne des M extensor indicis. Handchir Mikrochir Plast Chir 1988;20:93-6.

13. Magnussen PA, Harvey FJ, Tonkin MA. Extensor indicis proprius transfer for rupture of the extensor pollicis longus tendon. J Bone Joint Surg [Br] 1990;72:881-3.

14. Wilhelm K, Engert J, Habijanee S. Die indicis Plastic. Arch Orthop Trauma Surg 1978;91:229-32.

15. Levine J, Schneider M. Spontaneous rupture of the extensor pollicis longus tendon following the fracture of the carpal navicular bone. J Bone Joint Surg [Am] 1955;37:364-5.

16. Russel Moore J, Weiland AJ, Valdata L. Independant index extension after extensor indicis proprius transfer. J Hand Surg [Am] 1987;12:232-6. 